\title{
In Situ Spectroscopic Observation of Activation and Transformation of Tantalum Suboxides
}

\author{
Ke Wang ${ }^{1}$, Zhi Liu ${ }^{2,3}$, Tirma Herranz $\mathrm{Cruz}^{2}$, Miquel Salmeron ${ }^{2,3}$, and Hong Liang ${ }^{* 1}$ \\ 'Materials Science and Mechanical Engineering, Texas A\&M University, College Station, \\ Texas, 77843, USA \\ ${ }^{2}$ Materials Sciences and Chemical Sciences Division, Lawrence Berkeley National \\ Laboratory, Berkeley, CA 94720, USA \\ ${ }^{3}$ Advanced Light Source, Lawrence Berkeley National Laboratory, Berkeley, CA 94720, \\ USA \\ "Telephone : (979) 862-2623, Fax : (979) 845-3081, E-mail: hliang@tamu.edu
}

\begin{abstract}
Using ambient pressure X-ray Photoelectron Spectroscopy (AP-XPS), we were able to observe the process of oxidation of tantalum with different morphological parameters. Being able to trace surface evolution during oxidation, we evaluated activation energy of oxidation under the influence of strain and grain boundaries. It was found that the metal oxidized through three different stages and there was a transition stage where the phase transformation from suboxides to the equilibrium state of pentoxide. The applied stress and surface defects reduced the activation energy of oxidation.
\end{abstract}

\footnotetext{
'Corresponding Author: hliang@tamu.edu
} 


\section{Introduction}

In light of advancement in high temperature oxide superconductors, ${ }^{\prime}$ it has becone increasingly important to understand the oxidation kinetics in all stages involved. Such a study however has been difficult for transition metals that possess several valentc states involving multiple oxides. One of the key challenges in underslanding metal oxidation is lack of high resolution and in situ observation techniques. In the past, in situ investigation was restricted due to the requirements of high vacuum. ${ }^{2 \cdot 4}$ Furthemmore, oxidation is a dynamic process and observation of static conditions of a surface does not represent their real situations, 5,6 Recent development in ambient pressure X-ray photoelectron spectroscopy (AP-XPS) systems marte it possible to study metal surfaces at near-ambient conditions. ${ }^{7.9}$ The lechuique is beneficial to study materials with active electronic structures.

Metal oxidation has played important roles in fundamentals of materials and enginering applications. ${ }^{10.14}$ Oxidation is either respousible for corrosion or for protection of the same in the form of a passivation layer. ${ }^{11, i 5-18}$ It has been accepted that a metal oxidation process involves interactions of metals and oxygen on the surface. Sucl a process involves the chemisorption, surface oxidation, subsutface incorporation, and bulk oxidation. ${ }^{\text {II,19-23 }}$ The types of metal oxides and their relationships have not been well understood. 
Tantalum (Ta) is a noble netal that is known to have an equilibrium state of pentoxide. Studies have reported that non-equilibrium state of Ta oxides could exist. ${ }^{24,23}$ Disctetc state of Ta oxide was found at elevated temperatures with a shift of $4 \mathrm{f}$ core level

photoelectron spectia. ${ }^{20}$ Continued oxygen exposure at low temperature led to oxidation of $\mathrm{Ta}^{27,28}$ Such oxidation began on the surface and then bulk through an electric-fieldassisted diffusion mechanism. Most previous studies have bees based on thermal effects. In present research, we investigate oxidation mecluanișns of Ta under various nechanical and themal conditions. The Ta has five valence states. We propose a non-conventional approach to study tantalum oxidation though mechanical stimulation, Using the AP-XPS technique, we ate able to observe the initiation and growh of oxides on Ta of different surface morphological conditions. The activation energy of oxtdation was evaluated based on such conditjons.

\section{Experimental}

In present research, we conducted in situ high-resolution AP-XPS analysis of the oxidation process of polycrystal and single crystal (100) Ta. Subsurface incorporation and the kitnetics of the oxidation were studied undex oxygen pressure up to 0.1 Tort.

Satnple preparation: Single crysta! (100) $(99.99 \%)$ and polycrystal Ta $(99.9 \%)$ (Goodfellow) were used for this research. The polycrystal Ta contains crystal planes of (110), (200), (21I), and (220). The polycrystal samples were divided into two sets. One set was compressed and the other as received. 'The compressed samples were prepared by 
pressing the set of samples under a high pressure of about $16 \mathrm{GPa}$ using the lnstron Tensile Tester (Instron 4206).

An optical microscope (Polaroid DMC2) with polarized lens was used to characterize the grain boundary of test samples. Topographic and phase images at a small scale were obtained using an Atomic Force Microscopc (Nano-R, Pacific Nanotechnology Inc.) in the close contact mode.

The AP-XPS measurements werc cartied out at the beamline 9.3.2 of the Advanced Light Source (ALS) at the Lawrence Berkeley National Laboratory. The beamiline is equipped with a fixed angle $55 \mathrm{~m}$ spherical grating monochromater and the Physical Electronics hemispherical analyzer. ${ }^{29}$ The photoemission system was developed to operate at nearambient pressures (up to $1 \mathrm{Torr}$ ) and the sample can be heated up to $700 \mathrm{~K}$. Clean sample surfaces were preparcd by $\mathrm{Ar}^{+}$sputluting ( $2 \mathrm{koV}$ ) for 2 lus in the preparation chamber, then transferred to the ambient pressure chamber for spectra acquisition at the room temperature (RT) and $500 \mathrm{~K}$ under 0.1 lorr of oxygen. Experiments were designed to imitate the real oxidation process because that any high-lemperature oxidation starts with R'T oxidation. The Ta $4 f(h v=550 \mathrm{eV})$ and $\mathrm{O}$ 1s $(\mathrm{hv}=850 \mathrm{eV})$ speclra wete taken at the photon energy of $550 \mathrm{eV}$ and $\$ 50 \mathrm{eV}$ respectivcly to ensure the same electron kinetic energy, i.e., the identical depth infonmation for all elements of interest. 'lhe dymanic oxidation process was recorded with a $50 \mathrm{~s}$ interval during the measurement. Different photoelectron energies were applied in order to obtsin depth profiles of Ta af specses. The photoelectron spectra were measured at nomal-incidence geometry, and the binding energy (BE) was referenced to the Fermi edge. All spectra were nomalized by the 
corresponding energy-dependent X-ray photoionization cross sections. ${ }^{30} U_{\text {sing XPSpeak }}$ 4.1, the peaks were deconvoluted with asynmetric Gauss-Lorentz profiles after the subtraction of a Shitley background.

\section{Results}

Figure 1 shows the $\mathrm{Ta} 4 \mathrm{f}$ and $\mathrm{O}$ 1s spectra of the as-receival polycrystalline Ta under different oxidation conditions. Figures $1 a, b$, and $c$ provide the spectra right after sputter cleaning (la), after oxidation at room temperature (RT) (lb), and after oxidation at $500 \mathrm{~K}$ (1c). Futther deconvolution identifies different valence stales of Ta. From high to low binding energy $(\mathrm{BE})$, they are $\mathrm{Ta}^{5+}, \mathrm{Ta}^{3+}, \mathrm{Ta}^{2+}$, and mixture of $\mathrm{Ta}^{1+}$ and $\mathrm{Ta}^{9}$. The deconvolution also presents the evolution of each component. With oxidation, the area ratio of $\mathrm{Ta}^{5+}$ increases and others decrease. Figure $1 \mathrm{~d}$ compares the $\mathrm{O}$ 1s spectra of the sampte under differen1 conditions. Spectra after oxidation (at RT and $500 \mathrm{~K}$ ) have higher intensity than that of the sample after sputter cleasing. They aiso have the same peak center at $530.2 \mathrm{eV}$. This number is smaller than that after sputter cleaning ( $530.4 \mathrm{eV})$.

Figure 2 shows the Ta $A f$ and $O$ is spectra of the compressed polycrystalline Ta under different oxidation conditions. Figures $2 a, b$, and $c$ present the specira of right after sputter cleaning, after oxidation at room temperature (RT), and after oxidation at $500 \mathrm{~K}$, respectively. Spectrum deconvolution identifies all valence statcs of tantalum. From high to low binding energy (BE), they are $\mathrm{Ta}^{5+}$, mixture of $\mathrm{Ta}^{4+}$ and $\mathrm{Ta}^{3+}, \mathrm{Ta}^{2+}$, and mixture of $\mathrm{Ta}^{1+}$ and $\mathrm{Ta}^{0}$. The evolution of each component shows the same trend as in Figure 1. A comparison of the $O$ ls spectra is shown in Figure $2 d$. For polycrystal tantalum, the $O$ Is 
spectra shift of the compressed sample is similar to that of tho as-received. Spectra after oxidation (at RT and $500 \mathrm{~K}$ ) have the same peak center at $530.2 \mathrm{eV}$. The peak center of that after sputter clearing is at $530.6 \mathrm{eV}$.

Figure 3 shows the $T a$ and $D$ ls spectra of the single crystalline tantalum under different oxidation conditions. Figures $3 a, b$, and c provide tesulis that right after sputtering after oxidation at room temperature (RT), and after oxjdation at $500 \mathrm{~K}$. Through deconvolution, the same six valence states are identified as shown in Figure 2 and their evolution trend behaves the same as polycrystalline tantalum samples. Figure $3 \mathrm{~d}$ compares the $O$ ls spectre of the sample under different conditions. The peak center of the sjectra after sputter cleaning and oxidetion at the $\mathrm{RT}$ and $500 \mathrm{~K}$ are at $530.6 \mathrm{eV}$, $530.4 \mathrm{eV}$, and $530.2 \mathrm{eV}$, respectively. Results are different from that observed in the polycrystalline sample, which demonstrates the effects of crystal structure on the oxidation process.

For the as-received sample, the femporal evolution of Ta $4 f^{\circ}$ spectrum is plotted in Figures 4a and $b$ for oxidation at RT and $500 \mathrm{~K}$. There is no sign of peak shift in the spectra of oxjdation at RT. But for the oxjdation at $500 \mathrm{~K}$, a g'adual shift towand higher BE can be identified. There are two possibilities for such a shift. One is the formation of suboxides and the other is due to the magnetic field induced by the heating current. It was confirmed by the deconvolution results that the former is responsible for the shift. The formation of the suboxides causing the peak shift was reported.' 
For lie compressed sample, Figures $4 c$ and $d$ plot the lime evolution of $\mathrm{Ta} 4 \mathrm{f}$ spectum for oxidation at RT and $500 \mathrm{~K}$ respectively. The gradual peak shift is observed in both cases. The difference is that the sluift in oxidation at $500 \mathrm{~K}$ is more apparent than that in the as-received sanple.

For the single crystalline sample, the temporal evolution of Ta 4 f spectrum is plotted in Figures $4 \mathrm{e}$ and $\mathrm{f}$ for oxidation at RT and $500 \mathrm{~K}$. The gradual peak shift toward high BE is confirmed in both cases. Comparing with the as-received and compressed samples, the single crystalline sample exhibited the largest shift amplitude.

\section{Discussion}

\section{Oxiclaton Kinetles}

The process of oxtdation is discussed here. As shown in Figure 5a, the evolution of Ta ${ }^{5+}$ 4f during oxidation at room temperature follows a parabolic law, At $500 \mathrm{~K}$, as shown in Figure Sb, there are three distinguishable stages: oxjdation, transition, and stabilization. The oxidation stage is the formation of oxide. The transition stage is the phase transformation from suboxides to the pentoxide. This is seen as the ratio increase of the $\mathrm{TaS}^{+}$in Fignre 5 . The stabilization is the final stage when the oxidation is stablized wilh majority Ta pentoxide. According to our t'esults, the oxidation at $500 \mathrm{k}$ was dominated by the transition between tantalum suboxidies and pentoxide, which appeared to be promted by the temperature increase. 
The intital oxidation at toom temperature can be explained using the fraction of free surface area, Comparing to the single crystal tantalum, the polycrystalline Ta has larger surface area due to its grain boundaries end surface defects. These will supply sufficient active siles for oxygen to incorporate leading to subsequent oxidation. Similarly, the asreceived and compressed samples exhibit steeper slope than the single crystal one with excessive surface areas and defects, as shown in Figure 5a. Similar parabolic behavior had been reported in copper oxidalion. "I Our results are consistent with previously published data.

\section{Activation Energy of Tantalum Oxjdation}

The observed peak shifts in Figure 4 are plotted in Figures $6 a, b$, atd $c$ for as-received polycryslalline, compressed polycrystalline, and single crysialline, respectively. The results of as-recelved and compressed samples indicate the existence of two slopes. Differently from the as-received and compressed samples, the single crysta]line exhibits a linear shift of the peak center toward the high energy direction. The peak shifts suggest artemate oxidation processes underwent in each sample.

Figure 5a shows the time evolution of $\mathrm{Ta}^{5+} 4 \mathrm{f}$ during oxidation at $\mathrm{RT}$. The as-received, compressed, and single crystal samplos exhibit different betaviors while the as-received and compressed sampies present similar evolving trend. The single crystal sample gives a lower slope than the other two. A close inspection also revenals two steps at $2000 \mathrm{~s}$ and $4000 \mathrm{~s}$. 
The temporal evolution of $\mathrm{Ta}^{5+} 4 \mathrm{f}$ during oxidation at $500 \mathrm{~K}$ is provided in Figure $5 \mathrm{~b}$. Comparing that at $\mathrm{RT}$, the oxidation process at $500 \mathrm{~K}$ underwent ith a different manner. Three different oxidation stages (I-III) are observed. At the primary stage (I), the formation of tantalum pentoxide is slow. In the transition stage (II), the oxidation rate valies in three samples. The single crystal sample has the steepest gradient and ends up with the highest pentoxide ratio following by the as-received sample. The compressed sample has the slowest increase with the lowest pentoxide ratio. At the final stage (III), the formation of Ta penloxide reached a plateau and the oxidation became stabilized. The curves indicate that there is a limiting value for each sample. For the single crystal sample, the curve had a limiting value of $82.5 \%$ within a period of 1500 s. For the asreceived, the data lad a limiting value of $78 \%$ in a period of 2500 s. For the compressod, the curve reached a limiting value of $76.5 \%$ within a period of $2500 \mathrm{~s}$.

The observed results can be qualitatively explained by the Wanger model of oxjdation. In the theory, the metal oxidation proceeds via the diffusion of metel ions through a neutral oxide layer, which is a rate limiting process. ${ }^{32}$ The further oxidation of Ta to pentoxide is limited by the transportation of tantalum ions through the oxide film. Consequently, the oxidation process eventually will get stabilized.

The activation energies of these samples were calculated for the temperatures between $300 \mathrm{~K}(\mathrm{RT})$ and $500 \mathrm{~K}$ using the equation:

$$
\ln (k)=-\frac{E_{n}}{R} \frac{1}{T}
$$


liere the $T$ is absolute temperature (in Kelvin), $K$ is reaction constant. The activation energy $E_{a}$ can be obtained through cvolution of $\mathrm{Ta}^{3+}$ if against temperature at the oxygen pressure of 0.1 Torr. Results are shown in the Figure 3. From a semilogarithmic plot of the oxidation rate of tantalum versus $1 / T$, the $\mathrm{E}_{\mathrm{a}}$ was calculatcd to $\mathrm{b} \sim 59.7 \mathrm{~kJ} / \mathrm{mol}(0.62$ eV/atom) for the as-recoived polycrystalline sample, $-37.6 \mathrm{~kJ} / \mathrm{mol}(0.39 \mathrm{eV} / \mathrm{atom})$ for the compressed polycrystal, and $\sim 115.3 \mathrm{~kJ} / \mathrm{mol}(1.2 \mathrm{eV} / \mathrm{atom})$ for the single crystal. The calculated value for single crystalline sample is in agreenent with the reported value. ${ }^{33}$

Comparing the aclivation energy, it is noticed that the calculated value for the conpressed sample is $0.23 \mathrm{eV}$, less than the as-received We believe this can be due to the strain effect on the reactivity of metal surfaces. To address this issue, we used an optical microscope (OM) and an atomic force microscope (AFM), along with the AP. XPS to study the effects of strface morphological changes and stress on Ta oxidation.

During sample preparation, the tantalum foil was cut into small pieces with the dimension of $8.25 \mathrm{~mm} \times 8.46 \mathrm{~mm} \times 1,12 \mathrm{~mm}$. They are subsequently compressed under a $11,360 \mathrm{~kg}$ $(25,000 \mathrm{Lb})$ toad, i,e., in the pressure of $162.76 \times 10^{6} \mathrm{~kg}^{\prime} \mathrm{cm}^{2}$ or $\sim 16 \mathrm{GPa}$. Two heads of Instron (Model 4206) have larget area than the sample to awoid extra stress concentration. The high compressive stress is significant enougl to induce plastic deformation. Indeed, afler compression, the sample size was chenged to the dimension of $8.31 \mathrm{~mm} \times 9.25 \mathrm{~mm}$

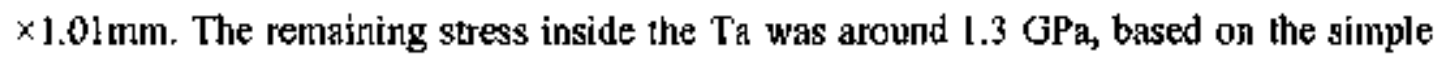
estimation through the stress-strain relationship. 
Our results (in Figure 5) showed that the pentoxide increases with time at a difterent rate for each specimen. The difference of single crystaltine and the polycrystal is in grain boundaries. Figure 8 is the oplical microscopic inage of tested samples. The polycrystalline Ta has visible grain boundaries. The height difference between grains varies from 30 to $40 \mathrm{~nm}$. The height vatiance of these grain boundaries seems to be reduced in the compressed sample. The surface defecls, defonation, and dislocations are expected to be introduced due to severe compression. The phase image of the AFM shows three saniple surfaces are relatively unfform indicating no exira phase exists. The AFM height inrage shows that the polycrystalline surface has a higher surface roughness yalue as compated with the single crystal one. This is due to the existence of grain boundaries. The compressed has a median roughness in comparison with others. Based the observation of surface morphology shown in Figure 8 , the higher oxidation rate of the as-received sample at room temperature (Figure 5 a) is due to the extra effects introduced through grain boundaries. At $500 \mathrm{~K}$, the as-received sample has a lower thansition rate than the single crystal one. Tluis indicates that the as-received sample has more suboxides than that of single crystal. The transition from suboxides to pentoxide seems to dominate the oxidation process.

It has been reported that sirained metal surfaces represented different chemical properties comparing with unstrained ones. One of the strain effects is the vibrational frequency shift of chemisorpted ges molecules such as $\mathrm{CO}$ (on $\mathrm{Cu}$ ). ${ }^{34}$ The other is the position of chemisorption ${ }^{35}$, where gas molecules prefer to stay at the position under a tensile stress and the compressed regions otherwise. ${ }^{36}$ In our case, the oxidation process underwent 
three stages: oxidation, transition, and stabilization. In the compressed sample, a $16 \mathrm{GPa}$ pressure was applied onto the sample in $Z$ direction and caused severe plastic deformation. The residual stress was mainly tensile on the surface and compressive in the $\mathrm{Z}$ direction. Based on previous studies, the compressive stress does not promote chemisorption of oxygen. This indicates that other factors such as diffusion and reaction might be dominants. The severally defomed Ta is expected to have tremendous amount of dislocations acting as hosting sites of chemisorption as well as diffusion paths. As a result, the oxidation took place with less energy barrier, in such, suboxides were formed easily. This can be seen clearly in the Figure 5b. The force-inducad suboxides of Ta has been reported in our electro-chenical mechanical exerperiments. ${ }^{24,25}$ As a matter of fach, the activation energy of the compressed sample is the lowest as compared with the other two, as listed in Table 1.

\section{Conclusions}

Using ambient pressure XPS, we have studied the oxidation kinefics of Ta (100) and polycrystalline samples. Our results demanstrate that there are thret distinguishable stages: oxidalion, transition, and stabilization. In the transition stage, there is a phase transformation from tantalum suboxides to pentoxide. The oxidation process at room temperature and $500 \mathrm{~K}$ exhibits quite different behaviors. At the room temperature, the transition state is dominant by the defects and grain boundaries. At $500 \mathrm{~K}$, the oxidation stage is well pronounced followed by the trangition. The transition was completed at around 1500 second and become stabitized. The cortesponding aclivation energies of 
oxidation werc obtained. Our results confintred the effect of residual stress at the sample sutface.

\section{Acknowledgements}

This research was sponsored by the National Science Foundation (0535578). The Advanced Light Source is supported by the Director, Ofive of Sciente, Office of Basic Energy Sciences, of the U.S. Department of Energy under Contract No. DE-ACO2$05 \mathrm{CH}\lfloor 1231$.

\section{References}

(1) Ohtomo, A.; Hwang, H. Y. Nature 2004, 427, 423.

(2) Campbel], C. T. Sclence 2001, 294, 1471.

(3) M. S. Chen; D. Kumar; Yi, C. W.; Goodman, D. W. Science 2005, 3/0, 291.

(4) G. Zheng; Altman, E. I, Surf. Sci. 2000, 462, 151.

(5) Ceyer, S. T. Scienke 1990, 249, 133.

(6) Ceyer, S. T. Acc. Chem. Res, 2001, 34,737.

(7) G. Ketteler; D. F. Ogletree; H. Bluhn; H. Liu; E. L. D. Hebenstreit; Saltneron, M. J. Am. Chem. Soc. 2005, $127,18269$.

(8) D. F. Ogletree; H. Bluhum; G. Levedev; C. S. Fatley; Z. Hussain; Salmeron, M. Rev. Sci. Instrum. 2002, 73, 3872.

(9) Salmeron, M.; Schlögl, R. Surf. Sci. Rep. 2008, 63, 169.

(10) Over, H.; Seitsonen, A. P. Science 2002, 297, 2003.

(11) Over, H.; Kim, Y. D.; Seitsonen, A, P.; Wendt, S.; Lundgren, E; Schmid, M.: Varga, P.; Morgante, A.; Ert], G. Science 2000, 287, 1474.

(12) Thurmer', K.; Willians, E.; Recutt-Robey, J. Science 2002, 297, 2033.

(13) Kresse, G.; Schmik, M.; Napetschnig, E.; Shislikin, M.; Kohicr, L.; Varga, P. Science 2005, $308,1440$.

(14) Nolte, P; Stierle, A.; Jin-Pltillipp, N, Y,; Kaspes; N.; Schulii, T. U.; Dosch, $\mathrm{H}$. Science 2008, 321, 1654 . 
(15) Hendriksen, B. L. M.; Frenken, J. W. M. Phys. Rev. Lett. 2002, 89, 046101.

(16) H. Demiryont; J. R. Siles; Geib, K. Appl, Opt 1985, 24,490.

(17) Chaneliere, C.; Aulran, J. L.; Devire, R. A. B.; Balland, B. Mat, Sci, Eng. $R$ 1998, 22, 269 .

(18) P.M. Natishan; E. McCafferty; P.R. Puckett; Michel, S. Corrok. Sci. 1996, 38,1043 .

(i9) Gustafson, J,; Mikkelsen, A.; Borg, $M_{1}$; Lundgren, E;; Köhler, L;; Kresse, G.; Schmid, M.; Varga, P.; Yuhara, J.; Torrelles, X.; Quirós, C.; Andersen, J. N. Phys, Rev. Lett. 2004, 92, 126102 .

(20) Lundgren, E.; Gustafson, J.; Mikkelsen, A.; Andersen, J. N.; \$tierie, A.; Dosch, H.; Todorova, M.; Rogat, J.; Reuter, K.; Scheffler, M. Phys. Rev. Lell 2004, 92, 046101.

(21) Carlisle, C. J.; King, D. A.; Bocquet, M. L.; Cerdá, J.; Sautet, P. Phys. Rev. Lett. 2000, 84, 3899.

(22) Lundgren, E.; Kresse, G.; Klein, C.; Borg, M.; Andersen, J. N.; De Santis, M.; Gaulhier, Y.; Konvicka, C.; Schunid, M.; Varga, P. Phys. Rev, Lett. 2002, 88, 246103.

(23) Li, W.X.; Stampfl, C.; Sclueffler, M. Phys. Rev. Lett. 2003, 90, 256102.

(24) Kar, P.; Wang, K.; Liang, H. Electrochimi, Acta 2008, 53, 5084.

(25) Kar, P.; Wang, K.; Liang, H. Electrochem. \&Solid-State Lett. 2008, 1/, 13.

(26) Himpsel, F. J.; Morar, J. F.; McFeely, F. R.; Pollak, R. A.; Hollinger, G. Phys, Rev. B 1984, 30,7236.

(27) Pan, X.-H.; Qju, S. L; Raaen, S.; Florit, M. I.; Shek, M. L.; Strongin, M. Phys. Rev. B 1987, 35, 3740 .

(28) Jacobsen, F. M.; Raaen, S.; Ruckman, M. W.; Strongin, M. Phys. Rev. $B$ $1995,52,11339$.

(29) Z. Hussain; W. R. A. Huff; S. A. Kellar; E. J. Moler; P. A. Heimarun; W. McKinney; H. A. Padmore; C. S. Fadlley; Shirley, D. A.J. Electron. Spectrosc. Relat. Phenom. 1996, 80, 40i,

(30) J. J. Yeh; Lindau, 1. At. Data Nucl. Data Tables 1985, 32,1.

(31) F. Gronind; Moller; P. J. Surf. Sci. 1987, 184, 530 .

(32) Wagner, C. Atom Movements; ASM: Cleveland, 1951.

(33) F. Degreve; Drowart, J. Metallwgre 1966, 6, 115 .

(34) Kampshoff, E.; Hahn, E, Kern, X. Phys. Rev. Lett. 1994, 73, 704.

(35) Gsell, $M_{;}$; Jakob, P.; Menzel, D. Science 1998, $280,717$.

(36) Mavrikakis, M.; Hammer, B.; Nisskov, J. K. Phys, Rev. Lett, 1998, 81, 2819 . 


\section{Figure and Table Legends}

Figure 1. XPS results of as-teceived polycrystalline tantalum. (a) Ta $4 \mathrm{f}$ after sputtering; (b) Ta $4 \mathrm{f}$ after oxidation at room temperature (RT); (c) Ta $4 \mathrm{f}$ after oxidation at $500 \mathrm{~K}$;

(d) Comparison of $O$ ls XPS results.

Figure 2. XPS results of compressed polycrystalline tantalum. (a) Ta $4 \mathbf{f}$ after sputtering; (b) Ta $4 f$ aftex oxidalion at room temperature (RT); (c) Ta $4 \mathrm{f}$ after oxidation at $500 \mathrm{~K}$;

(d) Comparison of $\mathrm{O}$ is XPS results.

Figure 3. XPS results of single crystalline tantalum, (a) Ta $4 f$ after sputering; (b) Ta $4 f$ after oxidation at room temperature (R'I); (c) Ta 4f after oxidation at $500 \mathrm{~K}$; (d) Comparison of O $1 \mathrm{~s}$ XPS results.

Figure 4. Time evolution of $\mathrm{Ta} 4 \mathrm{f}$ region during oxidation in 0.1 Torr $\mathrm{O}_{2}$. (a) Oxidation of as-received sample at RT; (b) Oxıdation of as-receivel sample at $500 \mathrm{Ki}$ (c) Oxidation of compressed sample at RT; (d) Oxidation of compressed sample at $500 \mathrm{~K}$; (e)

Oxidation of single crystal sample at RT; (f) Oxidation of single crystal sample at $500 \mathrm{~K}$.

Figute 5. Plol of the intensities of $\mathrm{Ta}^{\mathrm{st}}$ 4f nomalized to the total $\mathrm{Ta} 4 \mathrm{f}$ area as a function of lime for three samples. (a) Oxidation at RT; (b) Oxidation at $500 \mathrm{~K}$.

Figure 6. Peak shifts of Ta $4 f_{72}$ during oxidation at $500 \mathrm{~K}$. (a) As-received sample; (b) Compressed sample; (c) Single crystal sample.

Figure 7. Activation energy calculation of three samples oxidized at $500 \mathrm{~K}$.

Figure 8. OM and AFM images of Ta samples. (a) As-received Ta polycrystalline; (b) Compressed Ta polycrystalline; (c) Ta sitngle crystal (100),

Table I. Activation energy. 
Table 1. Calculated Activation Energy

\begin{tabular}{rcc}
\hline Samples & Activation Energy $(\mathrm{kJ} / \mathrm{mol})$ & Activation Energy (eV/atom) \\
As-received & 59.7 & 0.62 \\
Compressed & 37.6 & 0.39 \\
Single Crystal $(100)$ & 115.3 & 1.2 \\
\hline
\end{tabular}




\section{Table of Contents}

\section{In Situ Spectroscopic Observation of Activation and Transformation of Tantalum Suboxides}

Ke Wang, Zhi Liu, Tirma Herranz Cruz, Miquel Salmeron, and Hong Liang*

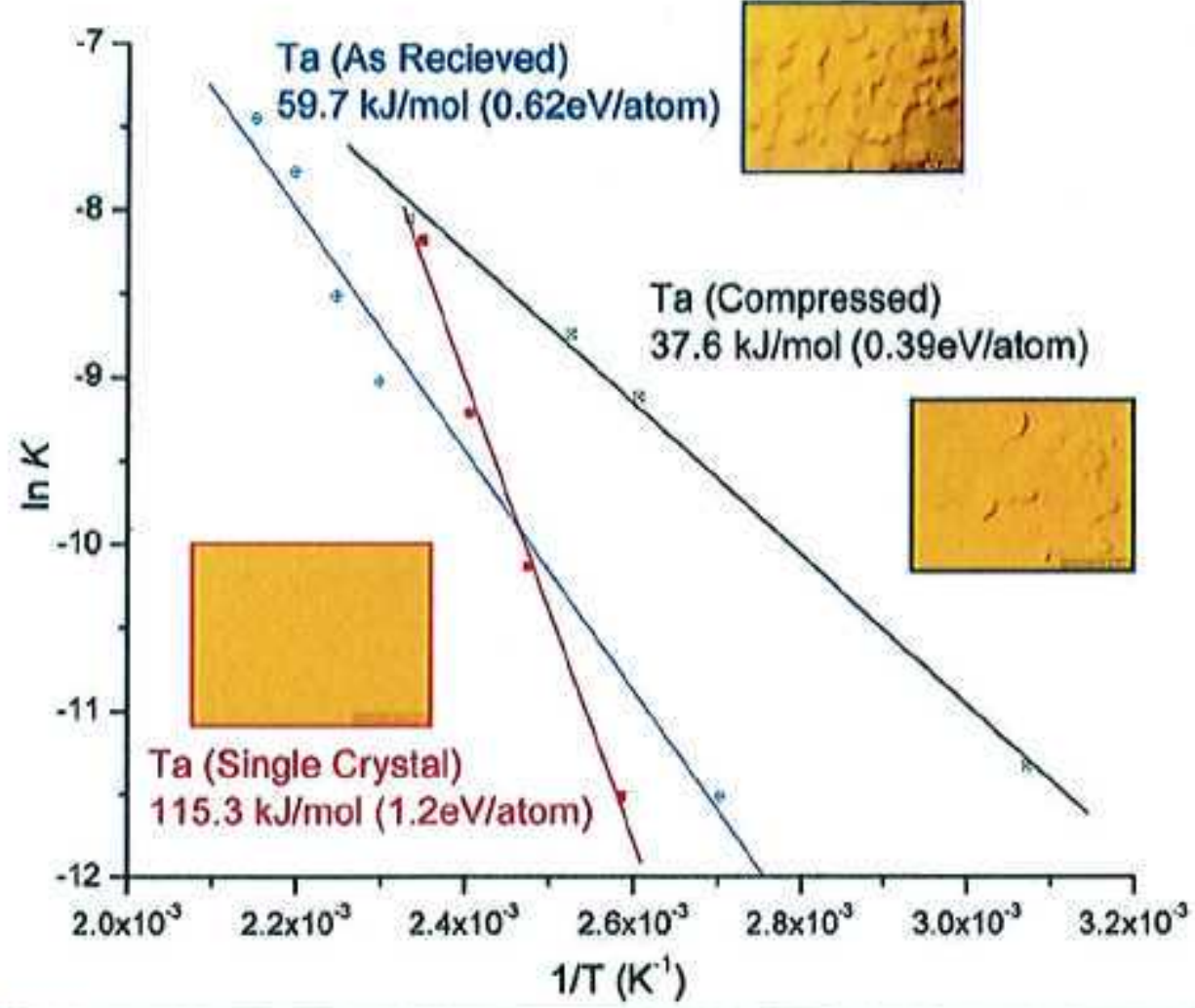

Abstract

Using ambient pressure X-ray Photoelectron Spectroscopy (AP-XPS), we were able to observe the process of oxidation of tantalum with different morphological parameters. Being able to trace surface evolution during oxidation, we evaluated activation energy of oxidation under the influence of strain and grain boundaries. It was found that the metal oxidized through three different stages and there was a transition stage where the phase transformation from suboxides to the equilibrium state of pentoxide. The applied stress and surface defects reduced the activation energy of oxidation. 

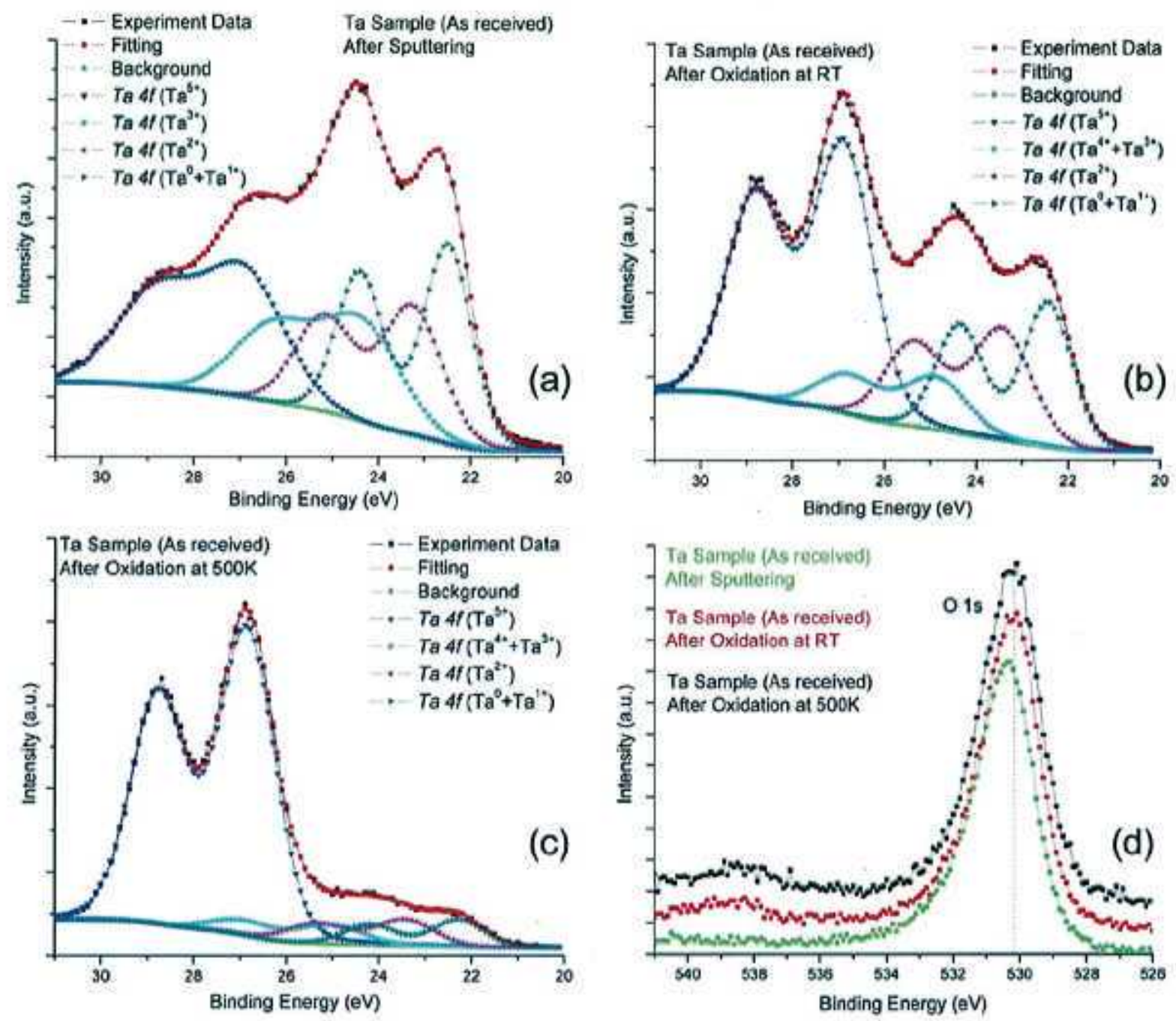

Figure 1. XPS results of as-received polycrystalline tantalum: (a) Ta $4 \mathrm{f}$ after sputtering; (b) $\mathrm{Ta}$ $4 \mathrm{f}$ after oxidation at RT; (c) Ta $4 \mathrm{f}$ after oxidation at $500 \mathrm{~K}$; (d) comparison of $\mathrm{O}$ is XPS results. 

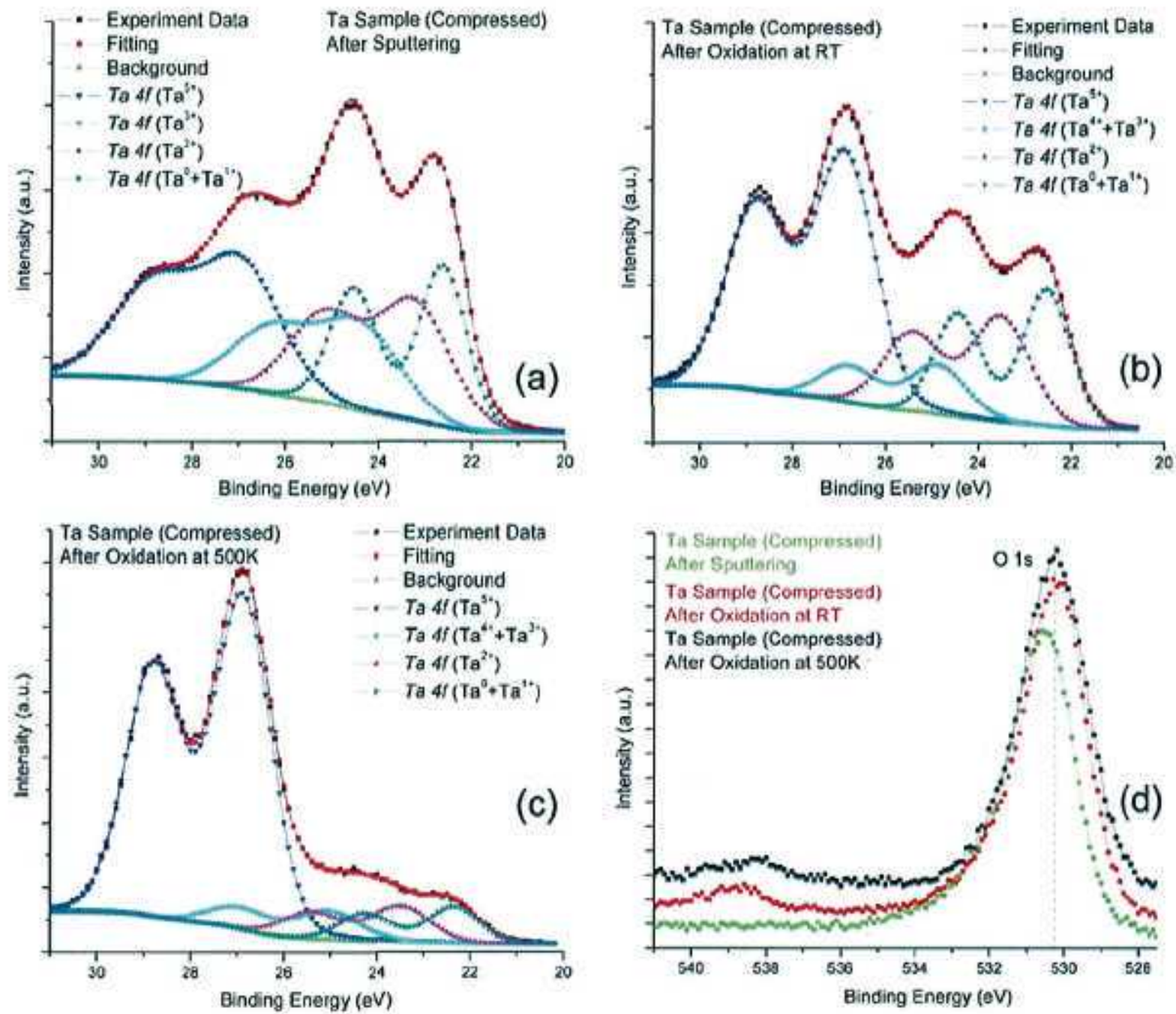

Figure 2. XPS results of compressed polycrystalline tantalum: (a) Ta $4 f$ after sputtering; (b) Ta $4 \mathrm{f}$ after oxidation at RT; (c) Ta $4 \mathrm{f}$ after oxidation at $500 \mathrm{~K}$; (d) comparison of $\mathrm{O}$ is XPS results. 

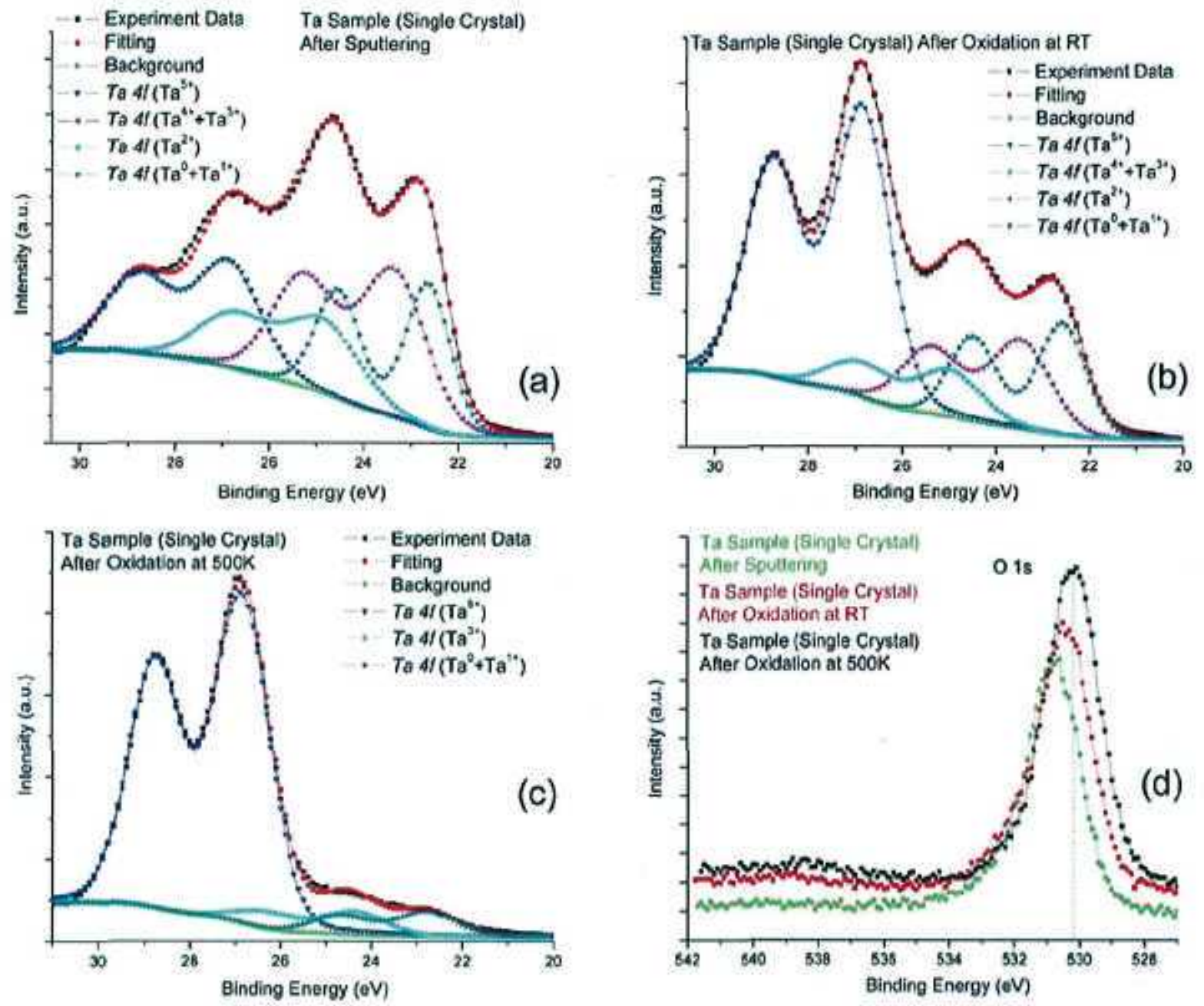

Figure 3. XPS results of single-crystalline tantalum: (a) Ta $4 \mathrm{f}$ after sputtering; (b) Ta $4 \mathrm{f}$ after oxidation at RT; (c) Ta $4 \mathrm{f}$ after oxidation at $500 \mathrm{~K}$; (d) comparison of $\mathrm{O} 1 \mathrm{~s}$ XPS results. 

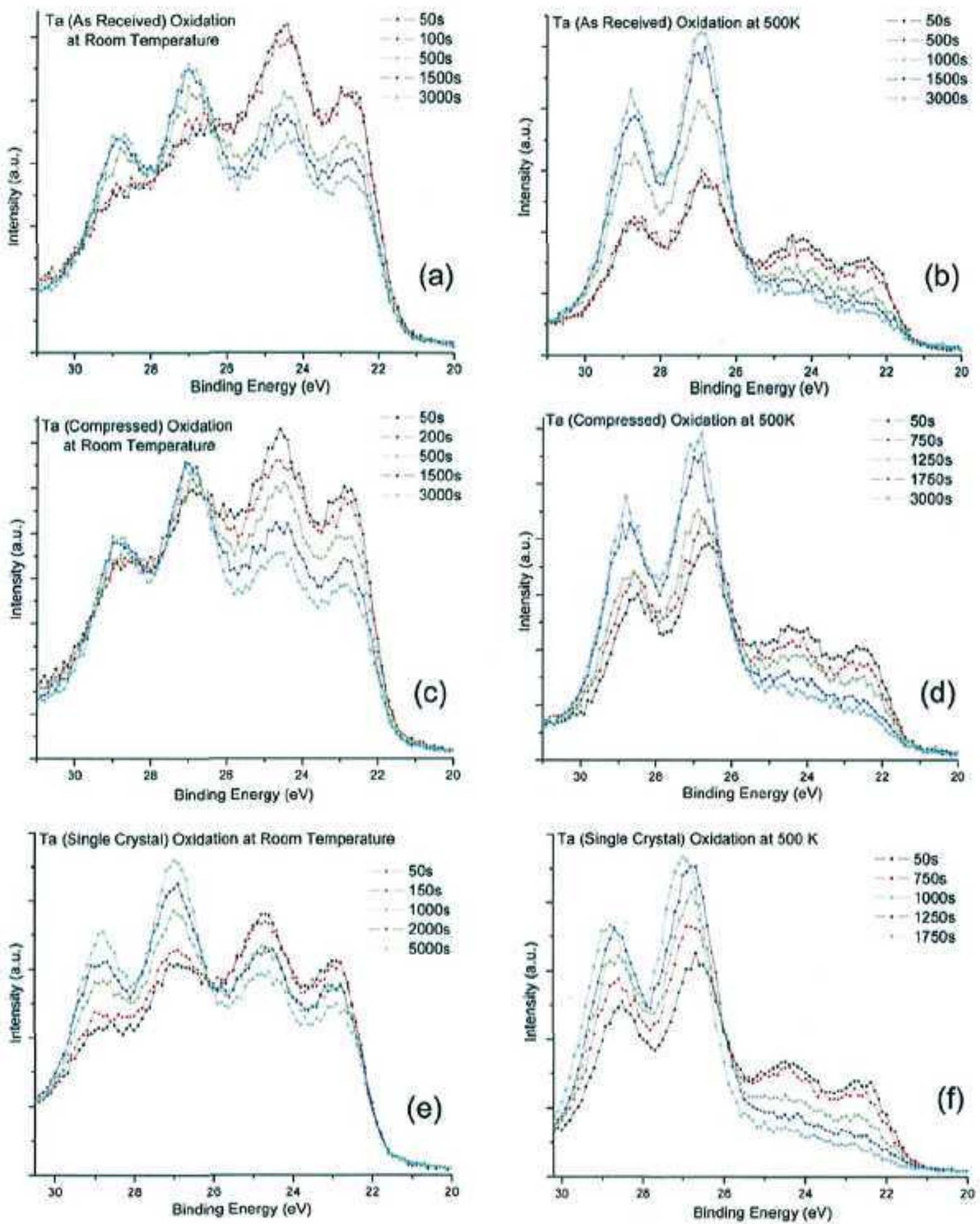

Figure 4. Time evolution of the $\mathrm{Ta} 4 \mathrm{f}$ region during oxidation in $0.1 \mathrm{Torr}$ of $\mathrm{O} 2$ : (a) oxidation of the as-received sample at RT; (b) oxidation of the as-received sample at $500 \mathrm{~K}$; (c) oxidation of the compressed sample at RT; (d) oxidation of the compressed sample at $500 \mathrm{~K}$; (e) oxidation of the single-crystal sample at RT; (f) oxidation of the single-crystal sample at $500 \mathrm{~K}$. 

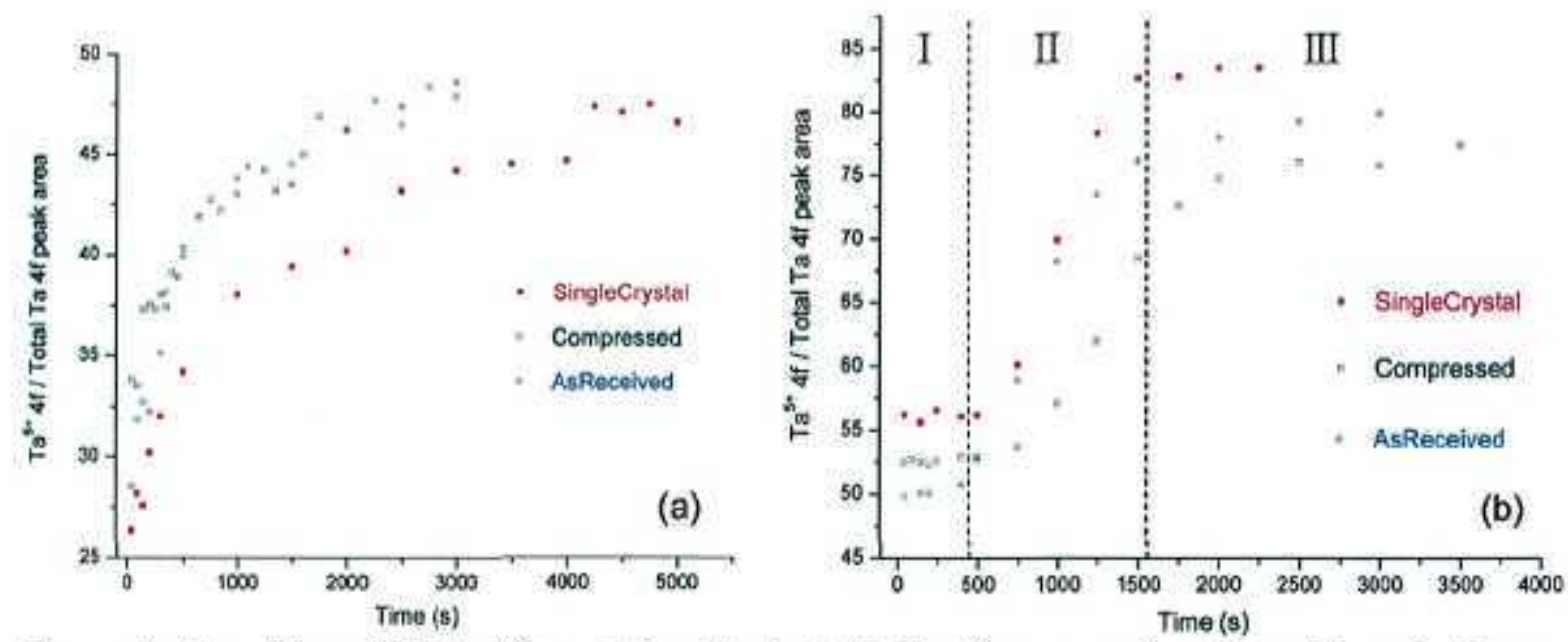

Figure 5. Intensities of $\mathrm{Ta} 5+4 \mathrm{f}$ normalized to the total $\mathrm{Ta} 4 \mathrm{f}$ area as a function of time for three samples: (a) oxidation at RT; (b) oxidation at $500 \mathrm{~K}$.
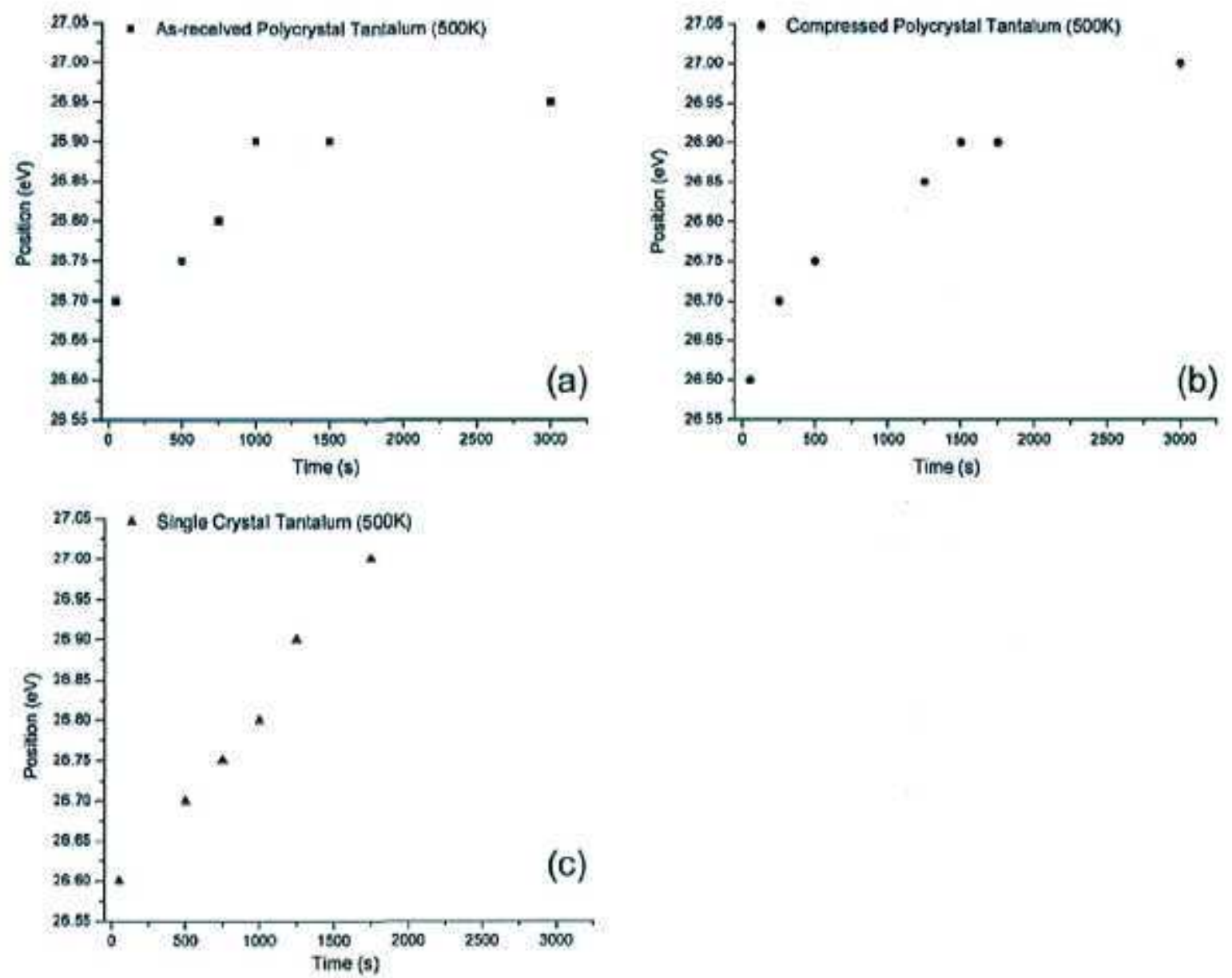

Figure 6. Peak shifts of Ta $4 f 7 / 2$ during oxidation at $500 \mathrm{~K}$ : (a) as-received sample; (b) compressed sample; (c) single-crystal sample. 


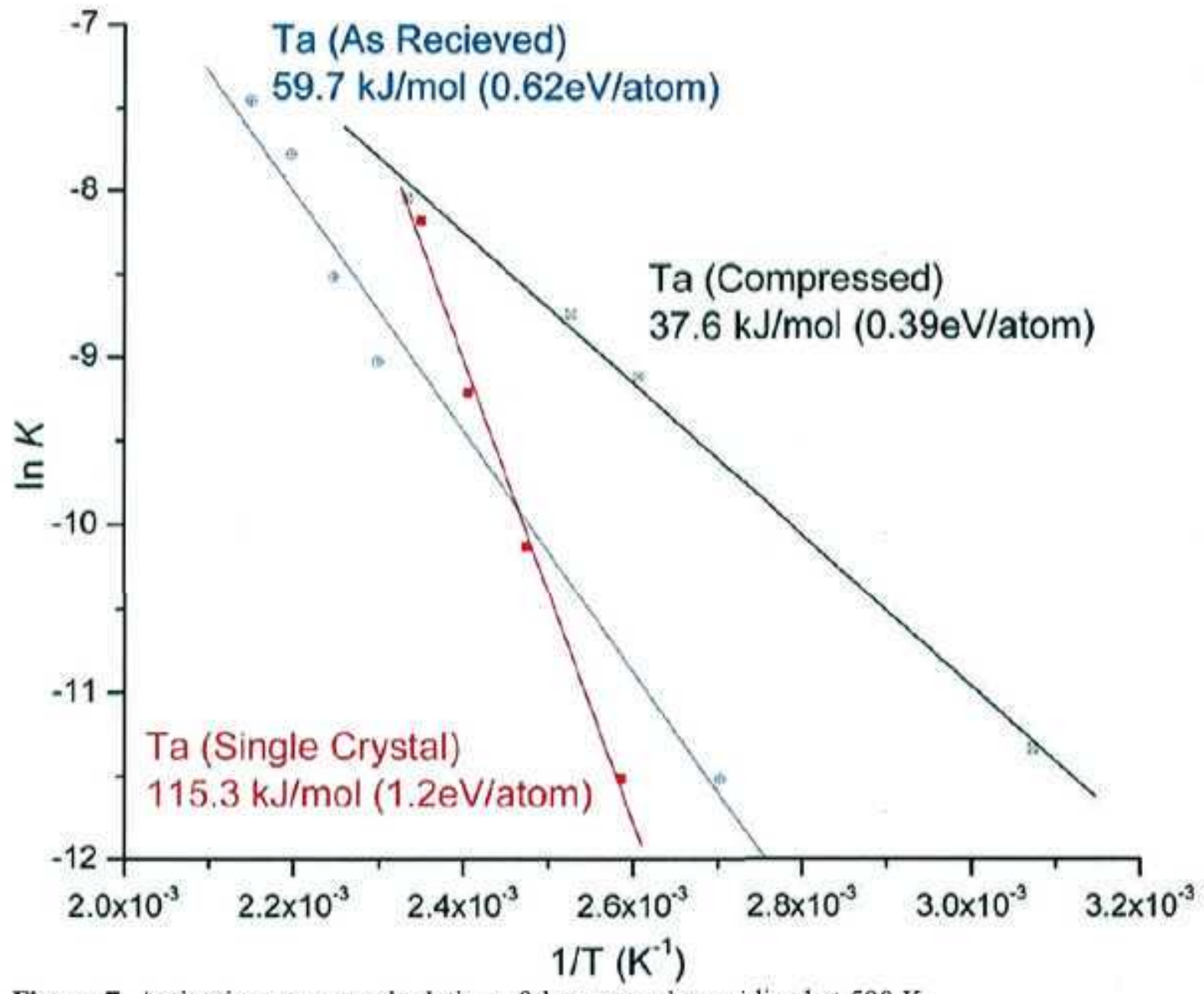

Figure 7. Activation energy calculation of three samples oxidized at $500 \mathrm{~K}$. 


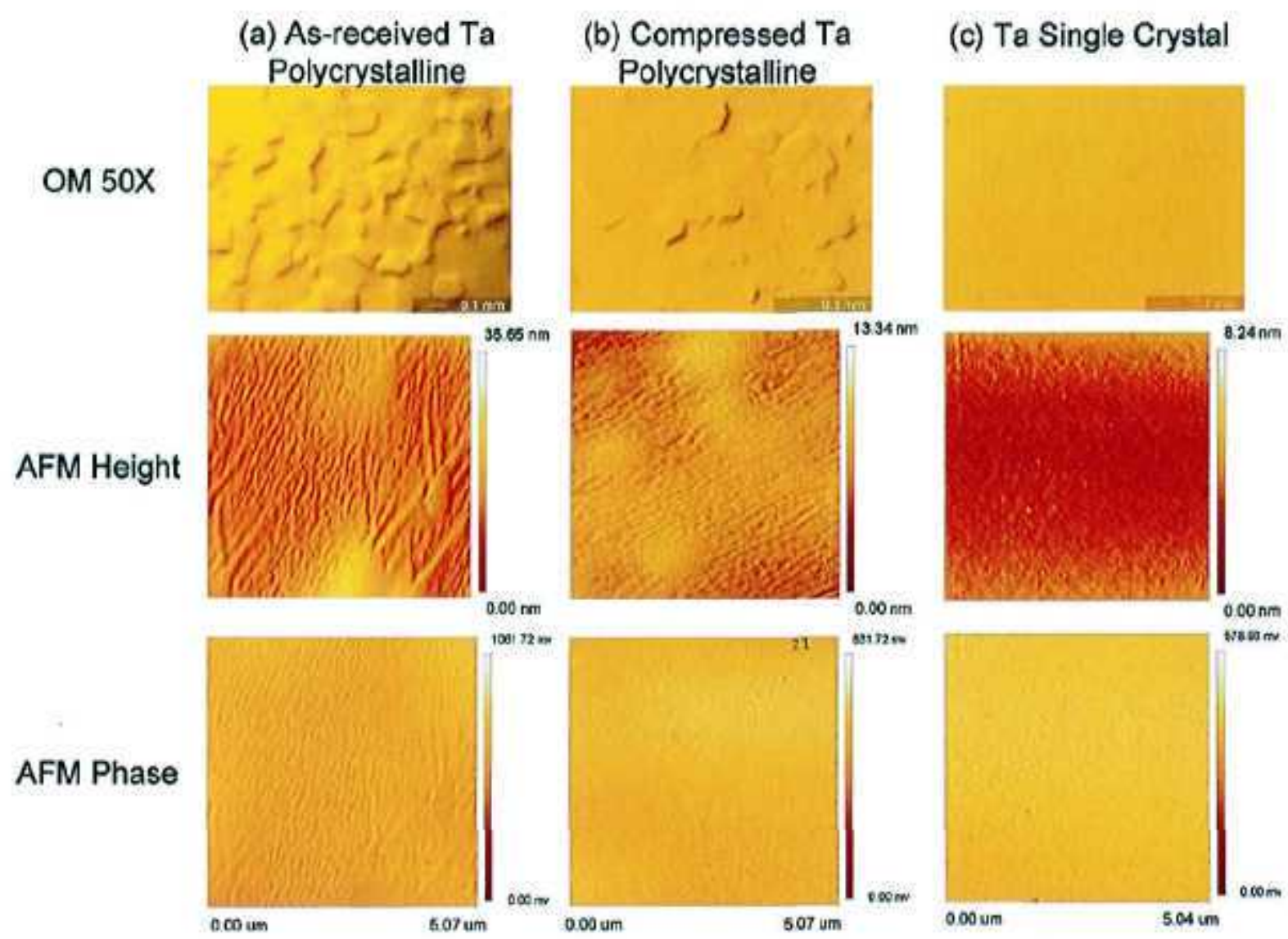

Figure 8. OM and AFM images of Ta samples: (a) as-received Ta polycrystal; (b) compressed Ta polycrystal; (c) Ta single crystal (100). 


\section{LEGAL DISCLAIMER}

This document was prepared as an account of work sponsored by the United States Government. While this document is believed to contain correct information, neither the United States Government nor any agency thereof, nor The Regents of the University of California, nor any of their employees, makes any warranty, express or implied, or assumes any legal responsibility for the accuracy, completeness, or usefulness of any information, apparatus, product, or process disclosed, or represents that its use would not infringe privately owned rights. Reference herein to any specific commercial product, process, or service by its trade name, trademark, manufacturer, or otherwise, does not necessarily constitute or imply its endorsement, recommendation, or favoring by the United States Government or any agency thereof, or The Regents of the University of California. The views and opinions of authors expressed herein do not necessarily state or reflect those of the United States Government or any agency thereof or The Regents of the University of California. 